\title{
SEXO: NATURALEZA Y PODER *
}

\author{
Sacramento Martí, Historiadora y \\ Angel Pestaña, Médico e Investigador biblogo
}

Esta reflexión surge de una preocupación por los fundamentos teóricoprácticos del feminismo y de la alarma ante la irrupción de una ideología biologista en la cultura contemporánea, tendente a interpretar la organización social y la divergencia social entre los sexos sobre la base de nuestra naturaleza animal. Nuestro ptopósito al escribir estas páginas se encamina a revisar críticamente las recientes experiencias del conocimiento sociocultural y biológico, desde una perspectiva intencionadamente feminista. Ello implica una reflexión acerca de la condición de la mujer a la luz del «destino» biológico y la contingencia cultural -en su sentido antropol6gico más amplio- unido a una crítica formal a ciertas teorizaciones actuales feministas y biologistas. Todo ello encaminado a establecer las bases para una sociedad culturalmente andrógina, más allá de una pretensión exclusivamente igualadora de los sexos.

El problema de los orígenes históticos de la opresión de la mujer es

* Introducción al libro de igual tftulo que aparecerá próximamente, editado por Nuestra Cultura, Madrid. 
un tema recurrente en la teotización feminista, desce los intentos de Engels y Bebel --loables, sin duda, pese a la insuficiencia de sus fundamen* tos antropológicos- para situarla en el marco conceptual del materialismo histórico. Pese a los casi 100 años transcurridos, puede decirse que es muy corto el camino andado, posiblemente debido a la enorme variedad y riqueza de las diferentes culturas históricas y a que buena parte de los esfuerzos de síntesís antropológica se han quedado atrapados en vías muertas para la comprensión histótica de la subordinación de la mujer, tales como el tabú del incesto o las relaciones de parentesco.

Como señala $\mathrm{J}$. Mitchell, ${ }^{1}$ todas las respuestas a la pregunta ¿cuándo comenzó todo?, tanto desde la perspectiva socio-económica, como desde su antípoda psicoanalista, contienen algo de verdad, pero nunca llegat a formar entre sí un todo coherente. ¿Quiere esto decir que hacemos preguntas sin sentido o carentes de respuesta? ¿O que las preguntas del cuándo y del por qué son preguntas falsas, como sostiene esta autora? Nuestro punto de vista es que el problema no reside en la pregunta, sino en los medios para contestarla. Es decir, en la incapacidad relativa de los campos aislados de las diferentes corrientes antropológicas, de la biología, de la sociología, de la historia, etc., para dar una respuesta coherente, no ya a la opresión de la mujer, sino a cualquier cuestión referente a la totalidad de la sociedad pasada o presente. El auge coyuntural y el afán hegemónico de las variadas disciplinas sociales, la rivalidad de diferentes cortientes dentro de una misma disciplina, han contribuido no poco a nuestra confusión actual. Frente a una antropología extasiada en el recuento detailado de las variables culturales, encontramos su antípoda en una antropología estructural que pretende reducir esa enorme variedad cultural a unos cuantos principios (¿innatos?) de comportamiento social; los mismos que una sociobiología de reciente factura pretende adscribir a unos suptestos «genes de la cultura», seleccionados y estabilizados por los mecanismos de ta evolución neodarwiniana. En este recuento apresurado, habría que situar también el materialismo histórico, víctima ab initio de la «primacía de lo económico» y la solución psicoanalista al dilema estructura/superestructura, tan en boga últimamente.

Estas insuficiencias no son, en cierta medida, sino expresión de un problema de crecimiento: es tanto el saber acumulado en el campo de inda" gación de cada disciplina particular, que sus mentores se sienten con fuetzas como para dar interpretaciones totales desde su particular punto de mira, incurriendo así en la tradicional ligereza intelectual de tomar la parte por el todo. Pero, en la medida en que ese avance del conocimiento es teal, las

1. J. Mitchell. Psicoanálisis y Feminismo, Anagrama, 1976. 
condiciones están maduras para revertir esta tendencia particularista, concentrando esfuerzos en la construcción de una auténtica ciencia de la cultura y de la sociedad, sobre las bases de una integración interdisciplinaria del saber acumulado. Esta confluencia sólo puede concebirse desde una jerarquía lógica de causa-efecto, en torno a la cual se puedan articular los aspectos contradictorios de la realidad observada y del pasado deducido.

En este sentido merecen destacarse los esfuerzos actuales para construit una ciencia de la cultura fundamentada sobre los datos de la infraestructura material que la soporta, mediante la integración de la variopinta tiqueza conceptual desarrollada por la biología evolutiva y la socio-ecología. Desde esta perspectiva, los recursos naturales y demográficos (otrora bestias negras del marxismo), junto con las relaciones tecno-ambientales, sistemas de apareamiento y crianza, salud y dieta, constituyen la interfase dinámica -siguiendo la acertada expresión de M. Harris- entre las constricciones de la naturaleza y la gran variedad de soluciones socio-políticas implementadas por las diferentes culturas.

Este tipo de abordaje extiende - a nuestro entender - los fundamentos del materialismo histórico, a la par que corrige sus defectos y omisiones. Algunas de estas últimas inciden de manera directa en el problema de Ia desigualdad histórica entre los sexos. En efecto, nada más importante para la producción social que la teproducción, es decir, la producción de los seres humanos. Y, sin embargo, al soslayar esta cuestión como un dato más de la raturaleza, ${ }^{2}$ se deja de lado, no sólo un parámetro importante para la determinación de la evolución socio-cultural sino, también, un elemento decisivo para interpretar el status social de la mujer en las diferentes culturas. El tema central de esta reflexión lo constituye la constatación, elemental pero frecuentemente olvidada, de un reparto desigual de las cargas fisiológicas de la reproducción que lleva a que la mujer soporte injustamente todos los costes sociales del mantenimiento de la población.

Una rápida ojeada a las costumbres, instituciones y leyes de la antigüiedad revela que en las sociedades más remotas —como la Babilónicala mujer aparece ya como la propiedad privada del esposo o padre, en tanto que mercancía con valor de cambio, materializado en su potencial reproductor. En este sentido nos parece que la noción del «valor econó

2. Es significativo cómo Marx elude la problemática de la reproducción de la especie... «y partiendo del supuesto de la existencia del individuo, la producción de la fuerza de trabajo consiste en la reproducción o conservación de aquéln. (K. Marx, El Copital, vol. I, Fondo de Cultura Económica, México, 1973, p. 124. Los subrayados en el texto original son nuestros: S. M. y A. P.) Nuesto autor no tuvo en cuenta que, con ese «supuesto», dejaba de iado la más decisiva contribución social de más de la mitad de la población. 
mico de los hijos», introducida por los demógrafos históticos para interpretar la autorregulación de la población, puede ser un instrumento valioso para el análisis histórico de la opresión de la mujer, eludiendo el economicismo «marxista-tradicional», con su énfasis en las leyes de la herencia, y el determinismo «feminista-radical», que todo to pretende explicar en la perversión ( ¿innata?) del padre-patriarca.

Peto el valor econónico de los hijos y el status social de la mujer son funciones históricas, que sólo tienen significado o valor explicativo en el contexto de la problemática de la población, de los recursos y del trabajo social, que debe afrontar cada cultura particular. Esto se pone claramente de manifiesto en las grandes transiciones culturales de nuestra historia. Así, el estudio de las sociedades de cazadores-recolectores que han sobrevivido hasta nuestros días, pone de manifiesto una preocupación exquisita por mantener la tasa de reproducción en equilibtio con los tecursos, recurtiendo a la utilización consciente de prácticas culturales anticonceptivas. La principal motivación para este autocontrol -de profundo significado socialreside, según D. E. Dummond ${ }^{3}$ en la necesidad experimentada por la unidad familiar de espaciar los partos de manera que no interfieran con las importantes tareas de la mujer en el aprovisionamiento extensivo, propio de esas culturas. Culturas que, no por casualidad, están dotadas de un status social relativamente igualitario para las mujeres.

Por el contrario, los nuevos condicionamientos culturales del sedentarismo, basado en la sociedad doméstica agrícola y el desarrollo ulterior de los Estados Tributarios - sustentados en la extracción forzada del excedente agrícola - dan lugar a un cambio profundo en la valoración de los hijos (y de las teproductoras) que pasan de ser una «carga» material a una «ventaja» económica. Estos factores convergen y se potencian en contra de la mujer, de forma que a una disminución de su trabajo social inespecifico, se asocia un aumento de valor en su cualidad biológica específica como reproductora. Se inicia así la larga marcha del sometimiento de la mujer, que se va a consolidar en las ideologías teligiosa y familiar-tradicional, las costumbres y las instituciones sociales, que todavía perviven en nuestra sociedad contemporánea, por esos fenómetoos de inercia que llevan a la paradójica pervivencia de lo pretérito, cuando las condiciones sociales ya no lo hacen necesatio.

Efectivamente, la presión derivada de la avalancha demográfica de los últimos cien afros, frente a unos recursos naturales litritados, hacen socialmente necesario el logro de un equilibrio demográfico que, en cierta tre-

3. Don E. Dummond. *The Limitation of Human Population; a Natural History, en Science, 187: 713 (1975). 
dida, no es sino el retorno a las condiciones primigenias. Por otra parte, las nuevas formas de organización social que teclaman las transformaciones profundas del aparato productivo y la quiebza de valores del pasado, incluyendo la misma "crisis» de la familia, permiten concebir un horizonte más libre de igualdad compatible con la diferencia. Bastatía para ello situar nuestras costumbres e instituciones en el nivel de racionalidad en que la secular evolución cultural nos ha situado en la segunda mitad del siglo xx. No es una empresa fácil, por el lastre de la ideología tradicional y el entrecruzamiento de las dimensiones económicas de la política de poblaciones pero, desde luego, cae en el campo de lo posible. Por lo que respecta a la mujer, habría que partir de una faceta fundamental, que no siempre ha merecido la debida atención. Nos referimos a la infravaloración social de su especial contribución a la especie, en términos de producción de vida, que ha conducido a la ocultación de los costes de la reproducción, con la cual, la desventaja biológica ha pasado a ser una desventaja social.

Biología y cultura se nos presentan así como elementos indisociables para describir la condición de la mujer, constituyendo, a la vez, los ingredientes básicos sobre los que se ha elevado la construcción ideológica de la feminidad. Sólo en la perspectiva de esta doble contradicción podremos dar respuesta a las cuestiones que surgen al intentar deslindar las desventajas biológicas de la mujer —una noción eminentemente cultural- en su condición -Claramente biológica- - de reproductora de la vida. Llegado este punto, es necesario constatar y combatir un elemento inquietante de nuestra cultura contemporánea, tendente a demostrar que la organización social —es decir, las jerarquías históricamente establecidas de sexos, clases o razas - es una consecuencia inevitable de nuestra naturaleza animal. Esta biología ideologizada encuentra en el dimorfismo sexual y en la subordinación histórica de la mujer un campo de experimentación idóneo, en el que actualizar las ideas innatistas más tradicionales, a la luz de las mo. dernas teorías biológicas.

El moderno discurso biologista sobre los sexos arranca de la noción neodarwiniana que considera a los individuos como "portadores de genes》 y en lucha abierta por expandirlos y perpetuarios en las generaciones sucesivas. En la escenificación de esta tragedia cósmica, existen dos tipos de personajes (los machos y las hembras) cuyo destino está inscrito en las estrellas, por la división impuesta en la reproducción sexual. El destino del macho será conseguir el acceso al mayor número posible de hembras fértiles, como vía para lograr el máximo de crías en las que perpetuar sus propios genes. De ahí que su estrategia reproductora tienda a ser de tipo extensivo, más preocupado por la cantidad que por los cuidados que garanticen la sobrevivencia de la prole. Por el contratio, la hembra - cuya 
capacidad reproductora está limitada por el carácter cíclico de la ovulación y el númeto de óvulos por ciclo- tenderá a adoptar una estrategia conservadora, de carácter intensivo, con el objetivo de maximizar la sobrevivencia del número limitado de crías que su fisiología le permite.

Para armonizar estas dos estrategias contrapuestas, la modetna teotía evolutiva de la selección sexual ha recurrido a la fórmula de la inversión parental. La idea que subyace en esta fórmula es la de que el esfuerzo inversor previo condiciona las inversiones ulteriores. Una noción cargada de prejuicios antropomótficos y que responde a intuiciones económicas de carácter capitalista. Baste para ello recordar la empresa económica del Concorde anglo-francés, cuyos enormes costos financieros obligaron a cuantiosas inversiones adicionales, cuando ya se preveía su fracaso económico. También viene a cuento la justificación de tantos esfuerzos bélicos adicionales sobre la base de la sangte previamente derramada.

La inversión parental del macho es muy pequeña, por tegla general, Limitándose a la producción e introducción de espermatozoides que, por ser muy pequeños y superabundantes, carecen prácticamente de valor de cambio. Por ello, la tendencia natural del macho es a desertar: abandonando a la madre y a las crías, para dedicarse al desarrollo de la fortaleza, agresividad y demás artes marciales necesarias para la competencia con los otros machos. En la hembra, por el contrario, la inversión parental previa es muy grande debido, entre otras cosas, a que los óvulos son de gran tamano -y requieren por tanto de mayor dispendio energético para su producción y mantenimiento- y a los obligados períodos de preñez y lactancia, al menos en los mamíferos. Esta gran inversión previa obliga a la herrbta a seguir invirtiendo más y más en las crías. De ahí los fuertes lazos materno-filiales.

Ahora bien, y éste es el punto crítico de la teotía, para maximizar esta inversión y conseguir sus objetivos de sobrevivencia de las crías, las hembras tienen que conseguir la cooperación del macho, recurriendo para ello a maniobras tendentes a aumentar su inversión inicial en la procreación. Así surgirían -por vía de la selección natural-- el recato y la coquetería femenina, encaminadas a ponérselo difícil al macho y a conseguir una mayor inversión parental, que le fuerce a proseguir invirtiendo en el cuidado de las crías. La resultante de estas dos líneas de fuetza datía lugat al comportamiento reproductor propio de cada especie. Este comportamiento dimórfico sería luego fijado por los mecanismos de la hetencia y se expresaría por medio de las hormonas sexuales, actuando en los períodos críticos de maduración del sistema nervioso central.

Las hormonas sexuales femeninas darían lugar a una feminización del cerebro de la hembra, que se expresaría por un predominio de las faculta- 
des verbales sobre las intelectivas, en función de una peculiar lateralización del cerebro. Las mismas hormonas determinarían el establecimiento de los estereotipos femeninos del recato, pasividad, actitudes maternales, mansedumbre hipócrita, contemplación del espacio interior, etc., etc. Por el contrario, el cerebro virilizado por la testosterona, maduraría hacia el desartollo de las facultades cognoscitivas, tales como la habilidad espacial y capacidad matemática. Esto, unido al desarrollo de la fortaleza física y la pulsión agresiva, situaría a los machos en las condiciones óptimas de competitividad que requiere la evolución cósmica de las especies.

Por si faltara poco, la antropología estructural y el psicoanálisis dictaminan que el intercambio de mujeres y el rol del padre son ingredientes indispensables para nuestro ingreso en la civilización. Toda una hermosa construcción científica que viene a demostrar lo que el chascarrillo popular había dictaminado tiempo ha: "la mujer en casa y con la pata quebrada». Sólo que el nuevo discurso sexista se reviste del boato y prosopopeya del más atroz cientifismo. Jugando, además, a favor de un papanatismo genetalizado que tiende a aceptar acríticamente el dictamen de la ciencia. Esto explica el notable éxito social de la sociobiología y su irrupción exultante en la cuitura contemporánea. Arrastrando incluso a cierta subcuitura feminista que - haciendo de la necesidad virtud- contrapone los valores de Ia feminidad a los energúmenos de la inevitabilidad del patriarcado.

Es imposible, por razones de espacio, una presentación y discusión pormenorizada de los contenidos de este discurso biologista. Aquí solo seña. laremos tres elementos genéricos que fundamentan la crítica epistemológica del biologismo. Uno de ellos es el abuso reduccionista, que pretende interpretaciones totales a partir de teorías parciales. Olvidando que el todo es mucho más que la suma de sus partes y que la cultura es un todo indivisible, la sociobiología fragmenta la riqueza de nuestro set cultural en una serie indefinida de rasgos supuestamente hereditarios o determinados genéticamente a través de las hormonas sexuales. $Y$ aquí reside, precisamente, el nudo gordiano del debate ambientalismo-innatismo, que remite a las cornplejas intervenciones entre herencia y medio ambiente que dan lugar al fenotipo del ser tealmente existente. La complejidad de este proceso caun sal -que incluye actividades enzimáticas múltiples, síntesis de proteínas específicas, comunicación intercelular, así como las complejas vías de maduración neural, pre y posnatal-- hacen que sea imposible predecir el aba. nico de fenotipos de comportamiento que pueden resultar de un mismo genotipo expuesto a diferentes condiciones ambientales. ${ }^{4}$ En este contexto

4. M. W. Feldman y R. C. Lewontin, «The bereability hand-up», Science, 190: $1163(1975)$. 
habría que resaltat la flexibilidad acultural» puesta de manifiesto por la socio-ecología en la multiplicidad de tecursos sociales desplegados por una misma especie animal expuesta a diferentes medios f́sicos. También habtía que rescatar los datos de la antropología cultural -hoy sepultada en el olvido por la avalancha sociobiológica - que hace tiempo demostró cómo «los rasgos de la personalidad que llamamos "masculino" o "femenino" van tan poco ligados al sexo como el vestido, los ademanes o la forma de peinarse que una sociedad, en una época determinada, asigna a cada sexo".5.

Otro elemento de crítica sistemática al biologismo lo constituye su utilización indiscriminada del principio de analogía, que pretende trasladar a los humanos las presuntas bases genéticas u hormonales del comportamiento social o sexual de las hormigas, las ratas o las aves. Llegado este punto es preciso destacar algo tan elemental, como olvidado, que es la tadical especificidad de lo humano, que lo hace irreductible a los parámetros científicos sobre los que se edifican las ciencias de la naturaleza. Aquí, el argumento nos lo suministra la propia genética molecular que ha establecido que el hombre y el chimpancé somos prácticamente idénticos desde el punto de vista genético, de maneta que compartimos más del 98 por ciento de los genes. Las pequeñas diferencias resultantes no permiten explicar las grandes divergencias en cuanto a morfología o comportamiento. Pero, sobre todo, no explican lo más específicamente humano, que nos separa radicalmente del resto de las especies animales. Nos referimos a las apti. tudes simbólicas de las que deriva la inmensa capacidad de cultura.

$\mathrm{El}$ dato tiene unas consecuencias epistemológicas decisivas para la empresa sociobiológica, que pretende dar cuenta de la organización social y de las relaciones entre los individuos sobre la base de su genoma. A la par invalida, en general, todo intento de construir una antropología social sobre los datos de las ciencias naturales. El problema ha sido admirablemente planteado por Edmund Leach en una reciente contribución al 150 aniversatio de la British Society for the Advancement of the Sciences, del que no nos resistimos a transcribir algunas de sus partes más televantes. ${ }^{6}$

Parte Leach de la confrontación del obispo Wilberforce con Huxley, en torno a la teoría evolutiva de Darwin. Como es sabido, Wilberforce proclamó entonces: «Cualquiera que sea la opinión de otras personas, yo nunca consideraría a los mozos del zoológico como mis antepasados.» A lo que Huxley respondió calladamente: «Antes preferitía descender del mono que de un obispo.» El trasfondo del debate era la noción religiosa que

5. Margaret Mead. Sexo y temperamento en las sociedades primitivas, Edit. Laia, 1978.

6. Edmund Leach. Men, Bishop and Apes, «Nature», 293: 19 (1981). 
considera al hombre como una criatura especial «hecha a imagen y semejanza de Dios». En este sentido, si el gradualismo evolutivo de Darwin fuera cierto, no debería haber discontinuidad, de forma que los chimpancés debieran tener algo de alma, al igual que los humanos. Tal doctrina podría ser aceptable para un budista o un hindú, pero era más de lo que el obispo podia admitir. A lo que Leach añade: «Y pienso que el obispo tenia razón.» «No creo - sigue Leach- que los humanos tengan alma inmortal pero, indudablemente, poseen una capacidad simbólica y verbal que hace de estas criaturas un tipo nuevo y único en la naturaleza. Entre otras cosas, porque de esta capacidad deriva la posibilidad de hacer elecciones concretas e imprevisibles y, sobre todo, planear simulaciones o engaños a gian escala.»

$\mathrm{Y}$ aquí teside, como señala Leach, la gran paradoja de las ciencias sociales, que las separan abiertamente de las ciencias naturales. Éstas pueden pretender la búsqueda de las leyes que rigen los fenómenos naturales, sobre la base de la neutralidad del observador que puede experimentar con ellos, sin interaccionar. Aquéllas carecen, por el contrario, de ese privilegiado punto de observación neutral, de forma que el investigador es a la vez arte y parte. Además, las ciencias sociales tienen que partir de la base de la capacidad de engaño y autoengaño de los humanos.

Estas consideraciones nos llevan directamente al tetcer aspecto de la crítica epistemológica del biologismo, que hace referencia a la intromisión de la ideología, de las modas, de los prejuicios y de todos los factores que se quiera de la subjetividad, en el propio proceso de elaboración cientifica de los temas humanos. Un problema apasionante que incide en la cuestión de la ideología del poder y el poder de la ideología. Como señala Chorover, ${ }^{7}$ los mejores instrumentos de control social siguen siendo los mismos que se vienen usando desde los comienzos de la historia: las ideas que los humanos sustentamos acerca del universo y de nuestro lugar en él: y, muy especialmente, aquellas ideas que pretenden definir en qué consiste, qué significa el ser humano. Desde el «mito de los metales» de Platón hasta la definición agustiniana de la «natural depravación humana», hay toda una teoría y una práctica política, en las que nociones precientíficas acerca de la naturaleza humana son utilizadas como instrumentos de poder, legitimadores de la estratificación social. El entramado de los mitos actuales acerca de la naturaleza humana es básicamente idéntico al de los mitos atcaicos, con la única diferencia de que sus argumentos se extraen de algo que tiene apariencia de ciencia. Y, puesto que la ciencia se considera en

7. S. L. Chorover, From Genesis to Genocide, MIT Press, Carmbridge, Mass, 1979. (Hay traducción castellana, H. Blume editoriaI.) 
nuestros días con mucho más respeto que el que los griegos clásicos concedian a sus dioses, el terreno para su instrumentalización con fines políticos es muy grande y su contenido atgumental más difícilmente cuestionable.

Por mecanismos que tienen que ver con to discutido anteriormente, la sociobiología se está estableciendo como nuevo paradigma antropológico y los "practicones» de esta teoría se afanan en recopilat datos concordantes con ella, eliminando a su vez todo aquello que la contradice. Se establece así un punto de confluencia entre la metodología interna de las disciplinas científicas y el objetivo social reconocido, que se expresa en forma de publicaciones, ayudas a la investigación y el eco favorable de la prensa y de los otros medios de comunicación. Esto crea un terreno abonado para la irrupción de todos aquellos elementos de la subjetividad, relaciones públicas, propoganda y oportunismo, que denunciara Feyarebend ${ }^{8}$ en la elaboración de las teorías científicas. De ahí el sojuzgar de la ideología sobre el discurso científico y el funcionamiento ideológico de la ciencia.?

Pero el impacto epistemológicamente negativo que subyace a todas estas críticas al biologismo no puede, sin embargo, inocentar el enorme agravio social que ha supresto para la mujer su condición biológica de reproductora. Por ello, aunque admitamos con Margaret Mead que la personalidad de los sexos es una creación social, no podemos minimizar la importancia del reparto desigual de las cargas de la reproducción. Algunas feministas, basándose en los probables adelantos de la tecnología anticonceptiva $y$ en la posibilidad de la reproducción in vitro, reclaman el concurso de la ciencia para abandonar definitivamente las servidumbres de la reproducción, como premisa de liberación. Esta idea nos parece desacertada por su considerable dosis de ciencia-ficción, además de encertar una gravísima contradicción con las mismas esencias del feminismo. Abogar por ella es tanto como admitir que la maternidad es un determinante insuperable de la condición de la mujer, cuando el análisis histórico demuestra que es la utilización de la maternidad y la ideología que de esta manipulación se ha desprendido, la responsable de la matginación y de la opresión histórica de la mujer.

Lo verdaderamente inquietante de este análisis es la instrumentación de la capacidad teproductora de las hembras humanas para los fines de una ingeniería social, cuyo objetivo setía el ajuste de la masa de la población a la cambiante coyuntura económico-social. La evolución de la política de poblaciones estadounidense en estos últimos cincuenta años es sumamente esclarecedota al respecto. El final de la II Guerra Mundial, con su teot-

8. P. Feyarebend. Contra el Método, Ariel, 1975.

9. J. Ibáñez. Más allá de la sociologia, Sigio XXX, 1979. 
ganización de la vida civil y el retorno de los soldados exige la vuelta al hogar de la mujet, tras su masiva incorporación a la economía de guerra. La presión ideológica para facilitar este trasvase, reforzando el papel de la familia y de la maternidad, crearon las condiciones pata el baby-boom, que habría de prolongarse hasta finales de los sesenta. Por el contrario, la crisis económica que se inicia en la pasada década, con su alarmante crecimiento del paro y el adobo de la crisis energética, determinaron una infle. xión en la política de población, caracterizada por una gran presión ideológica para contener la población (el «crecimiento cero» como deber de ciudadanía), la proliferación de centros de planificación familiar con facilidades para la implantación de pesarios, diafragmas o esterilización y una extensión de la legalización del aborto a buena parte de los estados de la Unión. De esta forma, la mujer estadounidense se iba a ver «liberada» de la función reproductora, a sus espaldas, y precisamente cuando las condiciones socio-económicas le eran más adversas para su realización como persona.

En contraste, buena parte de los estados centroeuropeos entran en la década de los setenta con una tasa de natalidad extremadamente baja y una población estacionaria o en disminución. La alatma ante lo que se prevé como un debilitamiento estratégico o productivo conduce en estos casos a un endurecimiento de las actitudes, otrora liberales, en materia de control de natalidad. Al mismo tiempo se ponen en matcha medidas económicas de carácter pronatalista pata persuadit a un número creciente de mujeres a que acepten el papel de reproductoras.

Uno y otto caso ponen de manifiesto el amplio margen de manipulación de que pueden ser víctimas las mujeres con objeto de ajustar sus compor. tamientos sociales y reproductores a las necesidades de la coyuntura. Esto justifica el que nuestra conclusión principal sea reclamar un ordenamiento legal y unas normas de convivencia y educación que garanticen una justa valoración de los costes sociales del mantenimiento de la vida, sobre la base del reconocimiento de la desigual distribución entre los sexos de las cargas biológicas de la reproducción.

A quienes se escandalicen por lo que pudiera considerarse como una legislación proteccionista, incongruente con la marcha histórica hacia la igualación, no les vendría mal una pasada por el Marx más genuino de la Crítica al Programa de Gotba, en aquellos pasajes roussonianos en los que establece: «El derecho igual es todavía el "derecho butgués" que, como todo derecho, presupone la desigualdad. Todo derecho consiste en la aplicación de una tegla única a hombres diferentes que, de hecho, no son idénticos, ni iguales (...). Para evitar estas dificultades, el derecho no debiera ser igual, sino desiguat, s. 